\title{
Leiomyomatosis-Like Lymphangioleiomyomatosis of the Colon in a Female with Tuberous Sclerosis
}

Seng Geok Nicholas Goh, M.B.B.S., Jean May Sian Ho, F.R.C.Path., Khoon Leong Chuah, F.R.C.P.A., Puay Hoon Tan, F.R.C.P.A., Wee Teng Poh, F.R.C.P.A., Robert H. Riddell, F.R.C.Path.

Department of Pathology (SGNG, JMSH, KLC, PHT, WTP), Singapore General Hospital, Singapore; and Department of Anatomic Pathology (RHR), McMaster University Medical Center, Hamilton, Ontario, Canada

\begin{abstract}
Smooth muscle lesions of the large bowel, excluding the rectum, are generally rare, and diffuse smooth muscle lesions, termed leiomyomatosis, are even rarer. In this report, we document, for the first time, leiomyomatosis-like lymphangioleiomyomatosis (LAM) of the ascending, transverse, and descending colon in association with bilateral renal angiomyolipoma (AML) in a 30-year-old Chinese female with tuberous sclerosis complex (TSC). She presented with protracted constipation for which a colectomy was performed. Histology disclosed multiple confluent nodular CD34 and CD117 negative smooth muscle proliferation within the large bowel wall, whereas the renal biopsy revealed typical features of AML. Interestingly, the epithelioid smooth muscle cells of both the colonic and renal lesions were HMB45 positive, suggesting that leiomyomatosislike LAM of the colon, pulmonary LAM and AML are closely related entities. The patient remained free of complications for the last five years after surgery. Leiomyomatosis-like LAM of the large bowel probably represents another manifestation of the tendency of TSC to be associated with proliferative lesions.
\end{abstract}

KEY WORDS: Colonic leiomyomatosis-like lymphangioleiomyomatosis, HMB45, Renal angiomyolipoma, Tuberous sclerosis complex.

Mod Pathol 2001;14(11):1141-1146

Copyright $($ C) 2001 by The United States and Canadian Academy of Pathology, Inc.

VOL. 14, NO. 11, P. 1141, 2001 Printed in the U.S.A

Date of acceptance: July 6, 2001

Address reprint requests to: Seng Geok Nicholas Goh, M.B.B.S., Department of Pathology, Singapore General Hospital, Outram Road, Singapore 169608; e-mail: gnick@pacific.net.sg; fax: 65-227-6562.
Tuberous sclerosis complex (TSC), an autosomal dominant tumor gene syndrome with an incidence of at least one in 10,000 at birth $(1,2)$, is characterized by protean clinical manifestations frequently associated with proliferative lesions involving multiple organ systems. Diagnostic criteria have been proposed using a constellation of primary, secondary, and tertiary features (2). It is believed that dysregulation of cellular proliferation and differentiation results in the development of lesional growth in many organs. Specific gastrointestinal tract manifestation in the setting of TSC has been occasionally described. Hizawa et al. (3) reported hamartomatous polyps in the rectosigmoid colons of 2 patients with TSC. Byard et al. (4) reported a solitary $5-\mathrm{cm}$ subserosal leiomyoma at the hepatic flexure of the colon in a 16-year-old girl with an established diagnosis of TSC. In the recently revised diagnostic criteria for TSC (2), the only gastrointestinal manifestation included is the presence of hamartomatous rectal polyps.

In this study, we detail concomitant diffuse smooth muscle proliferation of colonic leiomyomatosis-like lymphangioleiomyomatosis (LAM) and renal angiomyolipoma (AML) in a 30-year-old female with TSC who presented with prolonged constipation. To the best of our knowledge, this is the first report of colonic leiomyomatosis-like LAM in the setting of TSC.

\section{CASE REPORT}

A 30-year-old Chinese female with a history of TSC associated with mental retardation, seizures, shagreen patches on lower back, and facial angiofibromas presented with intractable constipation that was not responding to medical treatment. On physical examination, she was also found to have bilaterally enlarged kidneys. Besides facial angiofibromas and shagreen patches over the back, no other physical signs such as those referable to the respiratory system were noted. Chest X-ray performed did not show any abnormality. CT scans of 
the abdomen revealed bilateral renal enlargement without evidence of pelvycaliceal dilation. Laparotomy was carried out both as an exploratory procedure and with the intention of performing a colectomy to relieve her constipation. At laparotomy, both kidneys appeared similarly enlarged, and frozen section of a wedge biopsy of the right kidney revealed AML. Examination of the large bowel revealed multiple thickenings, and a subtotal colectomy was then carried out. Postoperatively, she recovered uneventfully, and a subsequent MRI of the brain before discharge showed tubers in the cortical gray, subependymal, periventricular, and subcortical white matter. Five years after the operation, she remains well.

\section{MATERIALS AND METHODS}

The main excision specimen comprising an extended right hemicolectomy was received in formalin. The specimen was prosected in a routine manner with extensive sampling of the lesional nodules and processed for routine hematoxylin and eosin (H\&E)-stained sections. The wedge of renal tissue received for frozen section was completely processed for histology after fixation in formalin.

Five- $\mu \mathrm{m}$ sections from formalin-fixed, paraffinembedded tissues were stained with antibodies against vimentin (DAKO, 1:200), smooth muscle actin (Sigma, dilution 1:800), desmin (DAKO, dilution 1:100), S-100 protein (DAKO, dilution 1:1400), HMB45 (DAKO, dilution 1:100), cytokeratin AE 1/3 (Ventana, \#250-2135, prediluted), CD34 (NCLEND, dilution 1:30), bcl-2 (DAKO, dilution 1:50), CD117/c-kit (NeoMarker, MS483-P1, dilution 1:20), estrogen receptor (DAKO, M7047, dilution 1:40), and progesterone receptor (NCL-PGR, dilution 1:70) using the avidin-biotin complex (ABC) method with microwave antigen retrieval technique, except for S-100 where no antigen retrieval technique was used, and progesterone receptor (PR) and estrogen receptor (ER), where pressurecooked method was used. Appropriate positive and negative controls were used throughout.

\section{Pathologic Findings}

The resected specimen consisted of terminal ileum (6 $\mathrm{cm}$ in length), appendix (4 cm in length), and colon (116 cm in length) reaching distally to include the sigmoid colon. The ascending, transverse, and descending colon were dilated, and the dilatation was most marked proximally, decreasing distally. The colonic wall was focally thickened by irregular, confluent masses that were pale in color and measured from $0.5 \mathrm{~cm}$ to $3 \mathrm{~cm}$ in diameter (Fig. 1). Some of these nodules protruded into the colonic lumen as sessile polyps, whereas occasional

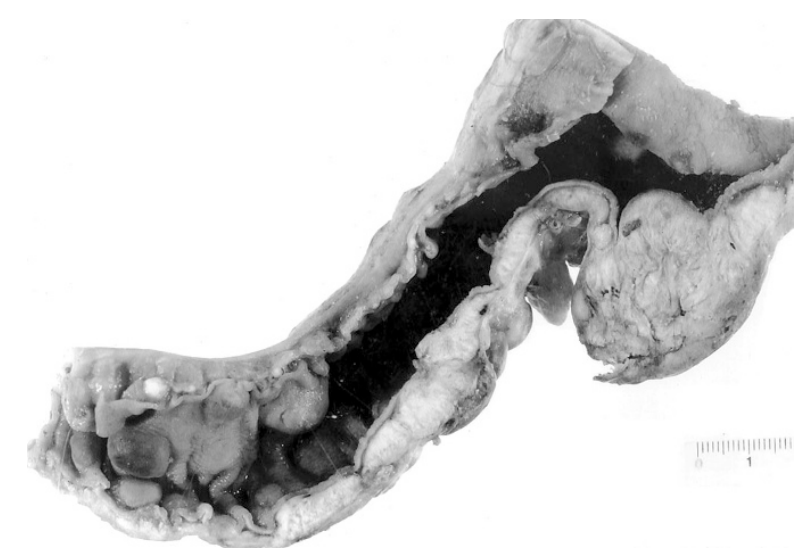

FIGURE 1. Colectomy specimen showing diffuse nodular thickening of the colonic wall.

nodules extended into the pericolic tissue. The sigmoid colon appeared to be uninvolved, but a separate $0.5-\mathrm{cm}$ diameter nodule was found in the mesocolic fat that was unattached to the colonic wall. The nodules showed no evidence of hemorrhage or necrosis, although one of the mucosal nodules showed surface ulceration. In the stretches of colonic wall between groups of nodules, the average diameter of the muscle wall showed focal circumferential thickening of up to $1 \mathrm{~cm}$.

Histologic examination disclosed that the nodules consisted of bundles of elongated spindle cells with markedly elongated nuclei (Fig. 2A) which were closely packed, affecting the muscularis propria with focal extension into the pericolic fat in some areas. There was little nuclear pleomorphism and mitoses were absent. The spindle cell areas alternated with more cellular areas made up of plump, epithelioid cells arranged around dilated, endothelial-lined channels. No mature adipose tissue was detected. The lesions extended in a pushing manner through the muscularis mucosae into the lamina propria but did not reach the luminal surface of the mucosa. The ulcerated nodule consisted of granulation tissue and an inflammatory cellular infiltrate overlying the lesion without the presence of lesional cells in the mucosal edges of the ulcer. An interesting feature was the irregular proliferation of smooth muscle possessing irregularly shaped slightly enlarged nuclei in the walls of the lymphatics that merged with the smooth muscle of the venous wall (Fig. 2B). This lymphangiomatous component did not involve the circumference of the lymphatic vessel uniformly and was more readily identified in the pericolic fat, being in close relationship with the nodular smooth muscle proliferation of the large bowel.

Sections of the sigmoid mesocolon nodule revealed similar features as those seen in the colonic smooth muscle lesion, being devoid of any adipose tissue component. 


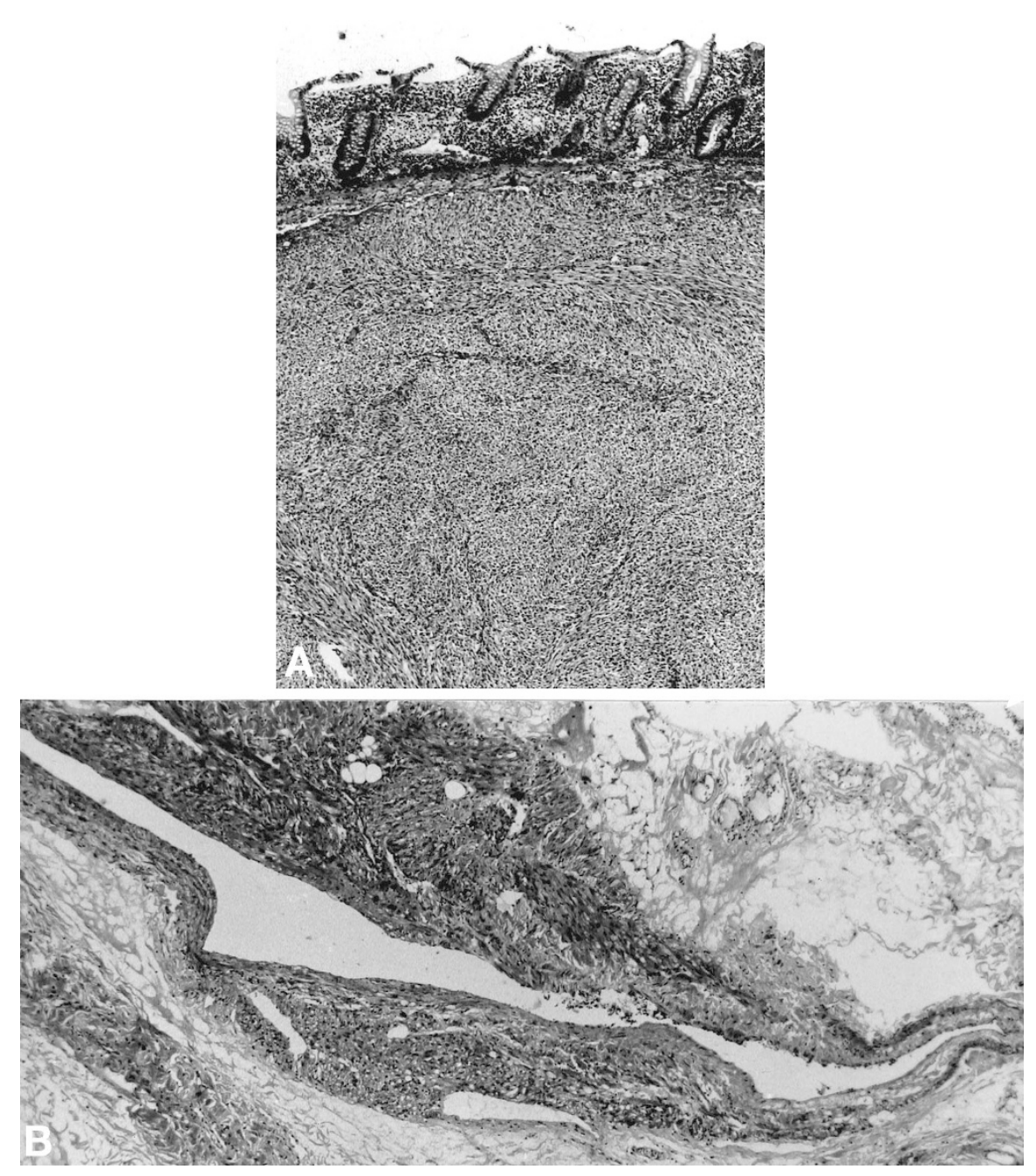

FIGURE 2. A, low-power view disclosing spindle shaped cells in the wall of the large bowel, sparing the mucosa. (H\&E, $40 \times$ original magnification). B, smooth muscle cells proliferating from the walls of a vein appearing to merge with the walls of the lymphatics in the colon. (H\&E, $100 \times$ original magnification).

On immunohistochemistry, both spindle cell and epithelioid cell areas showed positivity with smooth muscle actin, vimentin, and desmin, but S-100, ER, and PR stains were negative. CD34, CD117/c-kit, and bcl-2, immunohistochemical markers of gastrointestinal stromal tumor (GIST), were negative. HMB45 stained the epithelioid cells but not the spindle cell areas of the lesion (Fig. 3).

The wedge of renal tissue measured $2 \times 2 \times 1 \mathrm{~cm}$ and showed adipose tissue with firm areas on cut sections. Histology revealed a typical AML composed of mature adipose tissue interspersed with bundles of elongated cells with spindle-shaped nuclei which sometimes formed nodules and whorled masses. Some of the spindle cells radiated out of the wall of thickened blood vessels. There were also groups of plumper epithelioid-appearing cells in a hyalinized eosinophilic background that bore a striking resemblance to areas seen in the colonic smooth muscle proliferation (Fig. 4). No atypical epithelioid component was seen. The spindle and epithelioid cell areas stained positively for smooth muscle actin and desmin with positive HMB45 staining being confined to the epithelioid cells only. The renal AML did not stain with ER and PR antibodies.

\section{DISCUSSION}

Benign stromal lesions of smooth muscle origin, or leiomyomas, usually present as solitary circumscribed lesions in the gastrointestinal tract, showing predilection for the esophagus and anorectum (5). However (5), most tumors in the literature formally described as being of smooth muscle origin are better classified as gastrointestinal stromal tumor (GIST), which typically displays CD117 (c-kit) and CD34 immunoreactivity $(6,7)$. "Leiomyomatosis" is a term used to describe the occurrence of multiple, confluent masses in the bowel wall caused by multifocal proliferation of smooth muscle cells forming 


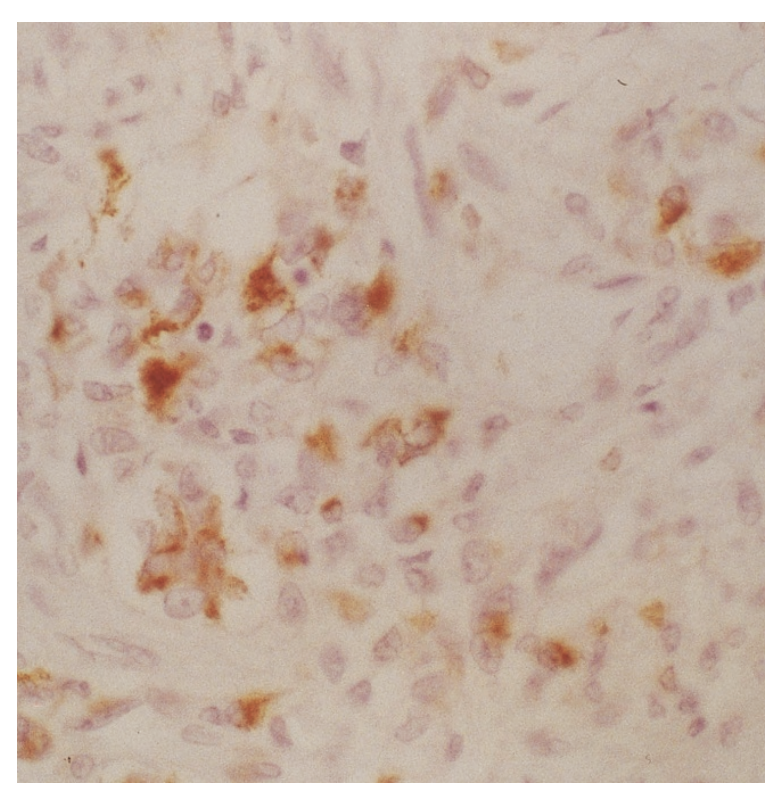

FIGURE 3. Antibodies against HMB-45 decorating only the epithelioid cells in colonic leiomyomatosis-like LAM. (ABC method, $400 \times$ original magnification).

focal tumor masses (8). In the gastrointestinal tract, diffuse leiomyomatosis is more often reported in the esophagus and upper gastrointestinal tract, being usually associated with X-linked Alport syndrome (9), but this is an uncommon event with fewer than 100 cases in the literature, most of which are single case reports $(9,10,11,12,13)$.

Leiomyomatosis of the colon is extremely rare, and only single case reports are found in the literature (14). Freni et al. (8) reported a semiconstricting multinodular lesion caused by smooth muscle proliferation in the muscularis propria, subserosa, and submucosa of the ascending and transverse colon in association with similar smooth muscle nodules in the mesocolon of a 30-year-old woman. Spaun et al. (15) reported colonic and mesenteric leiomyomatosis involving a 35-year-old mentally retarded male with multiple skeletal malformations and multiple intracranial meningiomas. The lesions in the serosa and mesentery of the colon contained adipose and neural tissue as well as thick-walled vessels, whereas the muscularis propria was disorganized and nodular. Vallaeys et al. (16) described a case with lesions similar to ours involving the small intestine and colon in a 64 year old female. The lesions were characterized by multifocal, diffuse tumor masses that were present in the muscular layers with extension into perimuscular subserosal fat. Histologically, they were composed of proliferating smooth muscle cells that often surrounded prominent blood vessels. They concluded that the lesion might be analogous to LAM. Brumback (17) raised the possibility that the muscle lesion described by Valleys may in fact represent a variant of

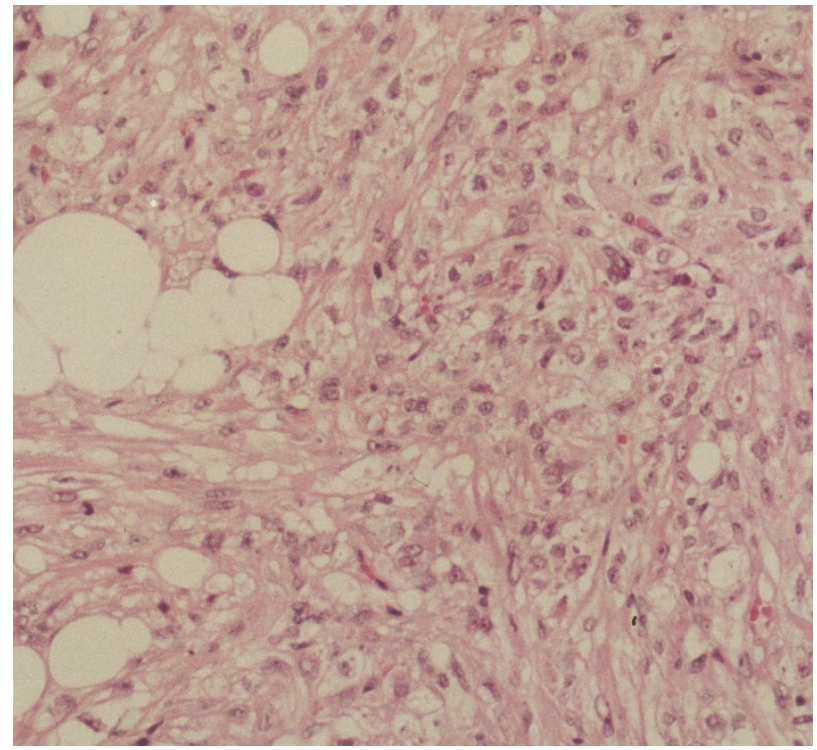

FIGURE 4. Renal angiomyolipoma disclosing spindle and epithelioid smooth muscle cells resembling the cells in the colonic leiomyomatosis-like LAM. Note the presence of adipose tissue. (H\&E, $200 \times$ original magnification).

leiomyomatosis peritonealis disseminata. Other instances of diffuse smooth muscle proliferation affecting the gastrointestinal tract include Sell and Cocco's (18) report of a case of diffuse leiomyomatosis of the gastrointestinal tract spanning from the esophagus to rectum in a 42-year-old man and the Zornig et al. (19) report of a case of diffuse leiomyosarcomatosis of the colon in a patient with ulcerative colitis. However, none of the patients mentioned above had any documented evidence of tuberous sclerosis. Furthermore, it is unclear whether any of the cases affecting the large bowel cited above may be related to GIST because they were reported in an era before the significance of CD34 and CD117 was appreciated (7).

We interpret the smooth muscle proliferation of the colon in this report as leiomyomatosis-like LAM for the following reasons. First, there are clinical and histologic similarities between the smooth muscle proliferation of the colon in our case and that seen in pulmonary LAM $(20,21)$, viz. the occurrence in a female of reproductive age with TSC and the histologic spectrum of changes that embody spindle and epithelioid smooth muscle cells surrounding endothelial-lined spaces in conjunction with a lymphangiomatous component and HMB45 expression. Furthermore, extrapulmonary LAM is a known phenomenon, having been described in mediastinal lymph node, retroperitoneum, and uterus $(22,23)$, and hence a colonic location in this instance does not exclude a diagnosis of LAM.

Interestingly, positive HMB45 staining in colonic leiomyomatosis-like LAM and renal AML in our 
case is confined to the epithelioid cells, whereas the spindle cells are HMB45 negative, a feature akin to the HMB45 staining characteristic in the epithelioid and spindle cells of pulmonary LAM described by Matsumoto et al. (21). These features implicate a close relationship between colonic leiomyomatosis-like LAM, pulmonary LAM, and AML. The association of renal AML is a well-known feature in LAM (20). In fact, the presence of HMB45 expression seen in the epithelioid smooth muscle cell of colonic leiomyomatosis-like LAM augurs well for the inclusion of colonic leiomyomatosis-like LAM into the family of lesions characterized by perivascular epithelioid cell (PEC) (22). PEC is described as epithelioid cell with clear to deeply eosinophilic cytoplasm associated with a perivascular location and the interesting co-expression of smooth muscle actin isoforms and melanogenesis marker, HMB45. PEC has been described in LAM, renal as well as extrarenal AML and clear cell "sugar" tumor of the lung, pancreas, and uterus. PEC is frequently associated with TSC. Reported lesions with PEC affecting tissues and organs related to the gastrointestinal tract $(22,24)$ include AML of the liver; clear-cell myomelanocytic tumor of the falciform ligament/ligamentum teres; and clear cell tumor of the pancreas, rectum, and serosal surface of the ileum. Apart from the $5-10 \%$ cases of hepatic AML being associated with TSC (22), none of the gastrointestinal tract related lesions with participation of PEC had documented TSC, thereby making our current case unique.

The question of whether the solitary nodule in the sigmoid mesocolon of our patient is a metastasis should also be addressed. The appearances suggest that the serosal nodule arose from smooth muscle proliferation in a vessel wall, being analogous to the smooth muscle proliferation from the blood vessels in the colon and thereby indicating that this is unlikely to be a metastasis. Moreover, the lack of mitotic figures and atypia in the colonic lesions or the mesocolon nodule makes a diagnosis of malignancy difficult despite the presence of muscularis propria involvement by lesional cells and apparent extension of lesional cells into the lamina propria, which are features of malignant largebowel GIST (14). On the other hand, the possibility of a metastatic renal AML has to be considered. Some authors view nodal deposits of AML in the setting of renal AML as multifocal AML rather than metastasis because no patients with classical renal and nodal AML (excluding epithelioid variant of renal AML) have progressed to a more widely disseminated AML (25). This reason and the fact that the mesocolon nodule bears a closer morphologic resemblance to the colonic smooth muscle lesion dissuade a diagnosis of metastatic AML. Probably, the serosal nodule in our case is akin to the mesocolon nodules seen in colonic leiomyomatosis de- scribed by Freni et al. (8), and the fact that our patient has been well for five years after the operation corroborates a benign course.

TSC is caused by mutations in either the TSC1 (chromosome 9q34) or TSC2 (chromosome 16p13) tumor suppressor gene (26), leading to increased cell proliferation (27-29). The lesions occurring in this disorder include cortical tubers and angiofibromas, which are considered hamartomas or "uncontrolled growths" rather than neoplasms $(1,2,26)$. However, renal AML is now considered a neoplasm of clonal origin and not hamartoma as previously thought (25). In fact, renal AML possessing a significant atypical epithelioid component has behaved in a malignant fashion $(25,30)$. Hence, the possibility of the colonic smooth muscle proliferation in this report being a neoplasm cannot be excluded, and study of additional similar cases is necessary to fully define its behavior and nature. Given the fact that HMB45-negative spindle cells of pulmonary LAM are shown to possess a high proliferating-cell nuclear antigen expression and are thus implicated in the progression of LAM (21), there is a likelihood that the colonic disease in our patient may progress without surgery because the colonic smooth muscle proliferation is composed predominantly of HMB45 negative spindle cells. In such an instance, surgery is appropriate for symptomatic relief and prevention of complications.

Acknowledgments: We thank our clinical colleagues, in particular Dr. Yik Hong Ho, who were involved in the management of the patient.

\section{REFERENCES}

1. Kwiatkowski DJ, Short P. Tuberous sclerosis. Arch Dermatol 1994;130:348-54.

2. Roach ES, Gomez MR, Northrup H. Tuberous sclerosis complex consensus conference: revised clinical diagnostic criteria. J Child Neurol 1998;13:624-8.

3. Hizawa K, Iida M, Matsumoto T, Tominaga M, Hirota C, Yao $\mathrm{T}$, et al. Gastrointestinal involvement in tuberous sclerosis. Two case reports. J Clin Gastroenterol 1994;19:46-9.

4. Byard RW, Phillips GE, Dardick I, Robertson E, Carter RF, Bourne AJ. Two unusual tumors of the gastrointestinal tract in a patient with tuberous sclerosis. J Paediatr Child Health 1991;27:116-9.

5. Miettinen M, Sarlomo-Rikala M, Lasota J. Gastrointestinal stromal tumors: recent advances in understanding their biology. Hum Pathol 1999;30:1213-20.

6. Miettinen M, Blay JY, Kindblom LG. Mesenchymal tumors of the colon and rectum. In: Hamilton SR, Aaltonen LA, editors. Pathology and genetics of tumors of the digestive system. Lyon, France: IARC Press; 2000. pp. 142-3.

7. Suster S. Recent advances in application of immunohistochemical markers for the diagnosis of soft tissue tumors. Semin Diagn Pathol 2000;17:225-35.

8. Freni SC, Keeman JN. Leiomyomatosis of the colon. Cancer 1977;39:263-6.

9. Thorner P, Heidet L, Moreno Merlo F, Edwards V, Antignac C, Gubler MC. Diffuse leiomyomatosis of the esophagus: 
disorder of cell-matrix interaction? Pediatr Dev Pathol 1998; $1: 543-9$

10. Guamer V, Garcia Torres R. Diffuse leiomyomatosis of the esophagus, tracheo bronchial, genital, and renal insufficiency. In: Demeester TR, Skinner DB, editors. Esophageal disorders: pathophysiology and therapy. New York: Raven Press; 1985. pp. 447-57.

11. Hamanaka S, Hamanaka Y, Yamshita Y, Otsuka F. Leiomyoblastoma and leiomyomatosis of the small intestine in a case of von Recklinghausen's disease. J Dermatol 1997;24:117-9.

12. Rosen RM. Familial multiple upper gastrointestinal leiomyoma. Am J Gastroenterol 1990;85:303-5.

13. Enterline H, Thompson J. Pathology of the esophagus. New York: Springer-Verlag; 1984. pp. 165-80.

14. Lewin KJ, Riddell RH, Weinstein WM. Mesenchymal tumors. In: Lewin KJ, Riddell RH, Weinstein WM, editors. Gastrointestinal pathology and its clinical implications. New York: Igaku-Shoin; 1992. pp. 299-310.

15. Spaun E, Nielsen L. Leiomyomatosis of the colon and mesentery: report of a case. Am J Gastroenterol 1986;81:385-8.

16. Vallaeys JH, Cuvelier CA, Bekaert L, Roels H. Combined leiomyomatosis of the small intestine and colon. Arch Pathol Lab Med 1992;116:281-3.

17. Brumback RA. Intestinal leiomyomatosis: a variant of leiomyomatosis peritoenalis disseminata? Arch Pathol Lab Med 1993;117:7-8.

18. Sell HW, Cocco A. Diffuse leiomyomatosis of the gastrointestinal tract in a single patient-esophagus to rectum: case report. Surgery 1997;122:637-40.

19. Zornig C, Thoma G, Schroder S. Diffuse leiomyosarcomatosis of the colon. Cancer 1990;65:570-2.

20. Carsillo T, Astrinidis A, Henske EP. Mutations in the tuberous sclerosis complex. TSC2 are a cause of sporadic pulmonary lymphangioleiomyomatosis. Proc Natl Acad Sci U S A 2000;97:6085-90.
21. Matsumoko Y, Horiba K, Usuki J, Chu SC, Ferrans VJ, Moss J. Markers of cell proliferation and expression of melanosomal antigen in lymphangioleiomyomatosis. Am J Respir Cell Mol Biol 1999;21:327-36.

22. Bonetti F, Pea M, Martigogni G, Zamboni G, Manfrin E, Colombari R, et al. The perivascular epithelioid cell and related lesions. Adv Anat Pathol 1997;4:343-58.

23. Matsui K, Tatsuguchi A, Valencia A, Valencia J, Yu ZX, Bechtle J, Beasley MB, et al. Extrapulmonary lymphangioleiomyomatosis (LAM): clinicopathologic features in 22 cases. Hum Pathol 2000;31:1242-8.

24. Folpe AL, Goodman ZD, Ishak KG, Paulino AFG, Taboada EM, Meehan SA, et al. Clear cell myomelanocytic tumor of the falciform ligament/ligamentum teres. Am J Surg Pathol 2000;24:1239-46.

25. Eble JN. Angiomyolipoma of kidney. Semin Diagn Pathol 1998;15:21-40.

26. Povey S, Burley MW, Attwood J, Benham F, Hunt D, Jeremiah SJ, et al. Two loci for tuberous sclerosis: one on 9q34 and one on 16p13. Ann Hum Genet 1994;58:107-27.

27. Miloza A, Rosner M, Nellist M, Halley D, Bernaschek G, Hengstschlager M. The TSC1 gene product, hamartin, negatively regulates cell proliferation. Hum Mol Genet 2000;9: 1721-7.

28. Jin F, Wienecke R, Xiao GH, Maize JC, Declue JE, Yeung RS. Suppression of tumorigenicity by wild type tuberous sclerosis 2 gene and its $\mathrm{C}$ terminal region. Proc Natl Acad Sci U S A 1998;93:9154-9.

29. Soucek T, Yeung RS, Hengstschlager M. Inactivation of the cyclin dependent kinase inhibitor p27 upon loss of the tuberous sclerosis complex gene-2. Proc Natl Acad Sci U S A 1998;95:15653-8.

30. Martignoni G, Pea M, Rigaud G, Mafrid E, Colato C, Zamboni $\mathrm{G}$, et al. Renal angiomyolipoma with epithelioid sarcomatous transformation and metastases. Am J Surg Pathol 2000; 24:889-94. 